University of Nebraska - Lincoln

DigitalCommons@University of Nebraska - Lincoln

Faculty Publications, Department of Psychology

Psychology, Department of

January 2007

\title{
Naltrexone renders one-session exposure therapy less effective: A controlled pilot study
}

\author{
Andrea T. Kozac \\ Western Michigan University \\ C. Richard Spates \\ Western Michigan University \\ Dennis E. McChargue \\ University of Nebraska-Lincoln, dmcchargue2@unl.edu \\ Katherine C. Bailey \\ University of Illinois at Chicago \\ Kristin L. Schneider \\ University of Illinois at Chicago \\ See next page for additional authors
}

Follow this and additional works at: https://digitalcommons.unl.edu/psychfacpub

Part of the Psychiatry and Psychology Commons

Kozac, Andrea T.; Spates, C. Richard; McChargue, Dennis E.; Bailey, Katherine C.; Schneider, Kristin L.; and Liepman, Michael R., "Naltrexone renders one-session exposure therapy less effective: A controlled pilot study" (2007). Faculty Publications, Department of Psychology. 271.

https://digitalcommons.unl.edu/psychfacpub/271

This Article is brought to you for free and open access by the Psychology, Department of at DigitalCommons@University of Nebraska - Lincoln. It has been accepted for inclusion in Faculty Publications, Department of Psychology by an authorized administrator of DigitalCommons@University of Nebraska - Lincoln. 


\section{Authors}

Andrea T. Kozac, C. Richard Spates, Dennis E. McChargue, Katherine C. Bailey, Kristin L. Schneider, and Michael R. Liepman 


\title{
Naltrexone renders one-session exposure therapy less effective: A controlled pilot study
}

\author{
Andrea T. Kozak ${ }^{\text {a,* }}$, C. Richard Spates ${ }^{\text {a }}$, Dennis E. McChargue ${ }^{\text {b,c }}$, \\ Katherine C. Bailey ${ }^{b}$, Kristin L. Schneider ${ }^{b}$, Michael R. Liepman ${ }^{a, d}$

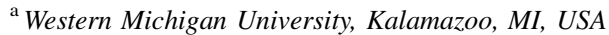 \\ ${ }^{\mathrm{b}}$ University of Illinois at Chicago, Chicago, IL, USA \\ ${ }^{\mathrm{c}}$ Edward Hines, Jr. VA Hospital, Hines, IL, USA \\ ${ }^{\mathrm{d}}$ Michigan State University/Kalamazoo Center for Medical Studies, Kalamazoo, MI, USA
}

Received 22 August 2005; received in revised form 26 January 2006; accepted 3 March 2006

\begin{abstract}
In vivo exposure has become the gold standard treatment for specific phobia. The endogenous opioid system is one mechanism proposed to explain why exposure provides such quick and effective treatment for specific phobia. The effect of naltrexone on fear and avoidance behavior was investigated among 15 specific phobia participants who received exposure treatment. Participants were randomly assigned to receive naltrexone, placebo, or no drug prior to attending one-session exposure treatment. Mixed effects regression results revealed that across time, the naltrexone group tolerated significantly less time in the room with the feared animal (Behavioral Avoidance Index) as compared to the placebo and no drug groups. Phobic individuals assigned to the naltrexone group had significantly higher fear ratings across time in comparison to the placebo group. Results provide support for the endogenous opioid system as a potential underlying biological mechanism associated with behavioral changes during in vivo exposure.
\end{abstract}

(C) 2006 Elsevier Ltd All rights reserved.

Keywords: Phobias; Naltrexone; Endogenous opiates; Behavioral assessment

Randomized controlled trials indicate that exposure is the most efficacious treatment for specific phobia (Booth \& Rachman, 1992; Menzies \& Clarke, 1993; Ost, Johansson, \& Jerremalm, 1982). It has been suggested that the specific variant of in vivo exposure is the treatment of choice for this disorder (Marks, 1987). Phobic individuals have been successfully

\footnotetext{
* Correspondence to: Department of Preventive Medicine, Northwestern University, Feinberg School of Medicine, 680 N. Lake Shore Drive, Suite 1102, Chicago, IL 60611, USA. Tel.: +1 312503 4749; fax: +1 3129087914.

E-mail address: akozak@northwestern.edu (A.T. Kozak).
} 
treated with one-session in vivo exposure in $3 \mathrm{~h}$ or less and have maintained a significant reduction in the key symptoms of fear and avoidance at subsequent 1-year follow-up sessions (Koch, Spates, \& Himle, 2004). Behavioral interpretations have been put forth to explain the mechanism of action that produces such effective and reliable outcomes. The most common interpretation is that severe distress levels are significantly reduced in the presence of phobiaspecific stimuli because of response extinction. In essence, extinction involves a reduction in the strength of learned responses through repeated responding that is not reinforced by escape or avoidance (Barlow, 1988). When phobic individuals are repeatedly confronted with fearful stimuli without the experience of negative consequences occurring, their fear and avoidance is significantly reduced. Less is known about the underlying biological mechanisms that may help to facilitate such processes.

A prime biological candidate that may be associated with behavioral responses during exposure therapy is the endogenous opioid system. Powerful and effective analgesic effects are produced by endogenous opioids (e.g., endorphins, enkephalins, and dynorphins) during inescapably aversive situations (Besson, Privat, Eschalier, \& Fialip, 1996; Hunziker, 1992; Hyson, Ashcraft, Drugan, Grau, \& Maier, 1982). In addition to their pain reducing effects, it has been suggested that opioids also have an anxiolytic (anxiety reducing) effect (Rang \& Dale, 1991). Individuals with specific phobia may be able to adapt via reduced fear and avoidance to an exposure intervention because of the release of these naturally produced analgesics. The influence of the endogenous opioid system on specific phobia treatment has been examined by comparing the effects of an opioid antagonist (naloxone or naltrexone) to placebo (Arntz, Merckelbach, \& de Jong, 1993; Egan, Carr, Hunt, \& Adamson, 1988; Merluzzi, Taylor, Boltwood, \& Gotestam, 1991). The common hypothesis is that an opioid antagonist would disrupt the effects of naturally produced endogenous opioids that are presumed to help a person with specific phobia adapt to exposure therapy, leading to behavioral disruptions in treatment such as early withdrawal from the treatment session (Merluzzi et al., 1991). The few studies that examined the effect of an opioid antagonist on specific phobia treatment show some evidence consistent with behavioral disruptions in treatment. Behavioral avoidance outcomes have shown that participants given an opioid antagonist had greater drop out rates (Merluzzi et al., 1991), took longer to complete one of the treatment steps (Merluzzi et al., 1991), and maintained a greater distance from the phobic stimuli during a behavioral assessment (Arntz et al., 1993).

To our knowledge, research has yet to address behavioral avoidance in terms of the duration a person is able to stay in the room with a feared stimulus during a behavioral assessment. Duration was of particular interest to the present study because opioid-mediated effects may be correlated with the length of time a person endures exposure to an aversive stimulus in an inescapable scenario such as exposure treatment. Results from non-human studies (i.e., rats exposed to inescapable shock) have found that 20 min of intermittent shock rather than 3 min of continuous shock is necessary for the opioid system to become activated (Maier, Sherman, Lewis, Terman, \& Liebeskind, 1983). At this point in time, one can only speculate as to the length of time required to activate the endogenous opioid system in humans. Phobics can be successfully treated in 99 min (Koch et al., 2004), suggesting that endogenous opioids may be released in 99 min or less.

The present study was designed to replicate and expand on data linking the opioid system with fear and avoidance behavior. Similar to previous studies, the present study employed a comparison between an opioid antagonist (naltrexone) and placebo. An additional no drug control group also was included to control for potential placebo effects (i.e., the activation of the endogenous opioid system due to the administration of a placebo; Amanzio \& Benedetti, 1999). There were two adaptive behavioral responses of interest: subjective reports of fear and duration 
(how long phobics were able to remain in the room during a behavioral assessment). We expected to replicate other findings (Egan et al., 1988) by revealing more fear responses across time for participants administered naltrexone compared to control participants. We further expected to expand on previous literature by showing that participants given naltrexone would not be able to remain in the room during the behavioral assessment as long as participants on placebo or no drug control conditions.

\section{Method}

\subsection{Participants}

Participants were recruited from two Midwestern universities and the surrounding community via flyers and announcements made in psychology department classes. Study sessions were conducted in the Anxiety Disorders Research Laboratory at the primary author's (ATK) university. Fifteen adult individuals (12 females, 3 males) with an average age of 22.6 years (range 18-40) participated in the study. With the exception of one participant, all were Caucasian. Most participants were students who worked full time or on a part-time basis. On average, these individuals had been phobic for a specific animal of experimental interest for 16.2 years (range 6-35 years). Ten participants had a fear of spiders, four feared snakes, and one feared mice. Since this study involved the administration of naltrexone and had the potential to evoke stress, some individuals were excluded from the study on the basis of medical conditions, opioid use, or possible pregnancy. Table 1 displays participant demographics for each group (naltrexone, placebo, no drug).

\subsection{Materials}

\subsubsection{Structured clinical interview for DSM-IV Axis I disorders-non-patient edition}

The Structured Clinical Interview for DSM-IV Axis I Disorders-Non-Patient Edition (SCID-I/ NP; First, Spitzer, Gibbon, \& Williams, 1996) is a semi-structured interview that allows one to diagnose a variety of different disorders categorized in the DSM-IV (American Psychiatric

Table 1

Participant demographics

\begin{tabular}{llll}
\hline Demographic & Naltrexone & Placebo & No drug \\
\hline Age (years) & 27 & 22 & 20 \\
Gender & & & 3 \\
$\quad$ Females & 3 & 6 & 1 \\
$\quad$ Males & 2 & 0 & 2 \\
Type of fear & & 5 & 1 \\
$\quad$ Spider & 3 & 1 & 1 \\
Snake & 2 & 0 & 11 \\
$\quad$ Mouse & 0 & 17 & \\
Duration of Fear (years) & 19 & & 0 \\
Past Treatment & & 3 & 4 \\
$\quad$ Yes & 1 & 3 & \\
$\quad$ No & 4 & & \\
\hline
\end{tabular}


Association, 1994). Concurrent, discriminant, and predictive validity for this semi-structured interview have been established (Kranzler, Kadden, Babor, Tennen, \& Rounsaville, 1996; Riskind, Beck, Berchick, Brown, \& Steer, 1987). The sections of the SCID-I/NP (First et al., 1996) administered during the in-person screening session in this study included psychotic, anxiety, mood, somatoform, substance dependence, and substance abuse disorders. The specific animal phobia section of the SCID-I/NP (First et al., 1996) was used to diagnose participants during an in-person screening session and was also administered at 1-week follow-up.

\subsubsection{Behavioral avoidance test}

The behavioral avoidance test (BAT) is an objective measure of a participant's avoidance behavior related to the feared animal. The BAT used in this study required the participant to initially stand in another room while the research assistant explained that he or she would be entering a room that contained the feared animal in an enclosed cage. The therapist instructed the participant to "Approach the animal as much as you possibly can and pick the animal up gently when you are ready." The therapist recorded the amount of time in seconds the participant remained in the room (duration) along with a Subjective Units of Discomfort Scale (SUDS) rating. SUDS ratings could range from 0 to 100 with 0 indicating "no anxiety" and 100 indicating that the participant was "experiencing the worst anxiety possible" (Wolpe, 1969). The main outcomes of interest in this study were subjective fear and avoidance behavior as measured by BAT. Fear was measured by self-reported SUDS ratings. Behavioral avoidance, also referred to as duration, was assessed by calculating the amount of time in seconds participants remained in the room with the feared animal during each BAT. The BAT was completed three times during the course of the study: once during the in-person screening session, once immediately after treatment, and once at posttest a week after treatment was completed.

\subsection{Procedure}

All project staff were trained and supervised by a fully licensed clinical psychologist (CRS). Five advanced graduate students and one advanced undergraduate student conducted assessments and treatment for this study. They were given detailed written procedures for the in-person screening session and 1-week follow-up session and used a manual to conduct treatment. Procedures for all sessions were discussed and reviewed during training meetings. Supervised practice sessions were conducted in order to determine that procedures were implemented correctly. Assessment and treatment sessions with each participant were not conducted by the same student.

Individuals interested in the study contacted the research phone line. They were provided information about the study and were scheduled for an in-person screening session during which they were interviewed with the SCID-I/NP and completed the baseline BAT. They were then scheduled for an evaluation with a psychiatrist (MRL) to determine if they were medically stable to participate in the study and had no contraindications. Participants who were ineligible during the in-person screening session or psychiatrist evaluation were provided referral information.

Eligible participants completed a treatment session approximately 1 week after the in-person screening session. All participants received the same exposure treatment, but were randomly assigned to receive naltrexone, placebo, or no drug. Both the therapist and participant were blind to whether the participant was assigned to the naltrexone or placebo condition. Forty-five minutes before treatment began, participants were administered a $50 \mathrm{mg}$ oral dose of naltrexone or identical appearing dextrose placebo. Researchers administered the pill $45 \mathrm{~min}$ before treatment 
in order to obtain the maximum blood level of naltrexone during treatment (Merluzzi et al., 1991). Although participants in the no drug group did not receive any medication, they were asked to come to the treatment session $45 \mathrm{~min}$ before treatment in order to rule out the longer therapist contact in the other two groups as a confounding variable.

The treatment used in this study was the behavioral one-session exposure treatment developed by Koch et al. (2004) that involves gradual in vivo exposure and modeling to the feared animal. A clear glass cage containing the feared animal was placed on a table against the far wall. A cage measuring $50.8 \mathrm{~cm} \times 47.0 \mathrm{~cm} \times 26.7 \mathrm{~cm}$ was used for the snake and a cage measuring $62.2 \mathrm{~cm} \times 32.4 \mathrm{~cm} \times 31.1 \mathrm{~cm}$ was used for the mouse and spider. During treatment, each participant approached the cage by walking on a large ruler that extended from the doorway to the cage. When all treatment components were successfully completed one time, the therapist and participant re-cycled through them again until reported (SUDS) levels were less than 20 on all components. Criteria for successfully ending treatment consisted of the participant holding the feared animal above the cage for at least one to three minutes and reporting minimal anxiety (reported SUDS level less than 20). Participants returned to the laboratory to complete a followup session 1 week later. During this session, they were interviewed with the specific phobia section of the SCID-I/NP and were asked to complete the BAT again.

\subsection{Human subject protection}

During the consent process, project staff explained to participants that they would receive naltrexone, a non-active placebo, or no drug during one-session exposure treatment. Participants were informed that the purpose of the study was to investigate one of the drugs for its effect on treatment outcome. They were not told whether the drugs would help facilitate or impede treatment outcome. They were informed that the investigators did not expect that the drugs constituted a treatment for participants' phobia, but rather the exposure session served as the treatment in this study. Participants were told that naltrexone is an opiate blocker that blocks natural pain relievers produced by the body and that the placebo contained dextrose. Potential side effects of naltrexone were described and discussed, which included nausea, a small transient rise in liver enzymes in the bloodstream, or inability to obtain pain relief from a narcotic pain killer for about 3-5 days after the drug is taken. All participants were also given a document describing naltrexone and were instructed to have a physician contact the psychiatrist (MRL) if injury or other painful condition suggested the need for opioid analgesics. This study was approved by the Human Subjects Institutional Review Board and the Institutional Animal Care and Use Committee at the university where sessions occurred. All procedures were carried out in accordance with the IRB approved protocol. Therapists were instructed to never leave participants alone with the feared animal and to use the guidelines set forth by the Institutional Animal Care and Use Committee if a participant got bitten during the procedures. All animals used in this study were non-venomous. External to the experiment, participants were offered an additional treatment session if they felt the first session did not effectively treat the phobia. They were informed that this session would be free of charge. Once data collection for the experiment was complete, debriefing information and the results of the study were provided to each participant.

\subsection{Analytic plan}

After examining whether group differences were present at baseline for age, gender, duration of fear, type of fear, and past treatment, two outcomes were examined using mixed effects 
regression modeling. Behavioral avoidance, or duration of time spent with the feared animal during the BAT, is referred to here as BAT duration. Fear measured by SUDS during the BAT will be referred to as BAT SUDS. Longitudinal analyses of the outcomes, BAT duration and BAT SUDS, at three time points (baseline, treatment and posttest) were analyzed using mixed effects regression modeling, implemented via SAS PROC MIXED that incorporated random intercepts with unstructured variance covariance structure. As recommended by Verbeke and Molenberghs (2000), this variance covariance structure for the longitudinal data was selected after comparisons with several other potential structures. Model covariates were whether participants had past treatment for any psychological disorder and the number of years they reported having their phobia. Both time and time squared terms were included in all analyses.

Specific tests were conducted to determine the effect of condition on BAT duration and BAT SUDS and time-related changes in both duration and SUDS (Group $\times$ Time interaction). Nonsignificant interaction terms were removed from the model in a backwards manner (i.e., Group $\times$ Time Squared first, and then Group $\times$ Time) and the model was refit. If both Group $\times$ Time and Group $\times$ Time Squared terms were nonsignificant, the model was refit including only the main effect of group (i.e., group difference averaged over all time points). In terms of the group comparisons, two a priori contrasts were estimated: (1) PLACEBO = placebo versus naltrexone treatment, and (2) NO DRUG = no drug versus naltrexone.

An advantage of using the MIXED technique is that it does not place restrictions on the number of observations per individual; thus, participants with missing data were not excluded from the analysis. Instead, model parameters were estimated with all data used in the analysis. This statistical model was developed for the longitudinal analysis of continuous variables (i.e., duration and SUDS rating during BAT), respectively (Diggle, Liang, \& Zeger, 1994).

\section{Results}

Five participants were randomly assigned to receive naltrexone, six were randomly assigned to receive placebo, and four participants were randomly assigned to receive no drug. Two participants in the naltrexone group and one in the placebo group dropped out of treatment early. One participant in the naltrexone group dropped out due to experiencing dizziness. The other two participants did not provide a reason for dropping out of treatment prematurely. The average number of treatment cycles for the naltrexone, placebo, and no drug groups were 3, 2.5, and 3.75, respectively.

A one-way analysis of variance (one-way ANOVA) revealed no group differences at baseline for age $[F(1,2)=2.903, P=.094]$ or for the number of years participants had their fear $[F(1,2)=1.855, P=.199]$. Chi-square analyses revealed no baseline group differences for gender $\left[\chi^{2}(2)=2.813, P=.245\right]$, type of fear $\left[\chi^{2}(2)=3.763, P=.439\right]$, or past treatment $\left[\chi^{2}(2)=3.239, P=.198\right]$.

\subsection{Duration of time with feared animal during BAT}

Longitudinal analysis of available duration data showed significant Group $\times$ Time interactions between the placebo contrast and the linear time trend and between the no drug contrast and the linear time trend (see Table 2). Fig. 1 displays duration means over time for the three treatment groups with available data. Over time, both the placebo and the no drug group spent a significantly longer time with the feared animal compared to those in the naltrexone group. 
Table 2

Predictors of duration of time spent with feared animal during the BAT

\begin{tabular}{lcrc}
\hline Variable & Regression coefficient & S.E. & $t$ \\
\hline Covariates & & & .96 \\
$\quad$ Past treatment & 25.206 & 26.286 & $-2.94^{* * *}$ \\
$\quad$ Years of phobia & -4.745 & 1.615 & $4^{* * 53^{* * *}}$ \\
Time effects & & & $-2.81^{* *}$ \\
Time & 163.52 & 36.086 & 16.465 \\
Time & -46.258 & & $-1.76^{*}$ \\
Group effects & & 28.935 & $-1.83^{*}$ \\
Placebo & -50.828 & 32.129 & $2.40^{* *}$ \\
No drug & -58.867 & 23.726 & $2.34^{* *}$ \\
Placebo $\times$ Time & 56.846 & 23.189 & \\
No drug $\times$ Time & 54.346 & & \\
\hline
\end{tabular}

Note. Predictors of duration of time spent with feared animal during the behavioral avoidance test (BAT) from baseline through posttest determined by mixed effects regression with available data.

** $\begin{array}{rl}{ }^{*} & P .10 . \\ \text { *** } & P<.05 . \\ & P<.01 .\end{array}$

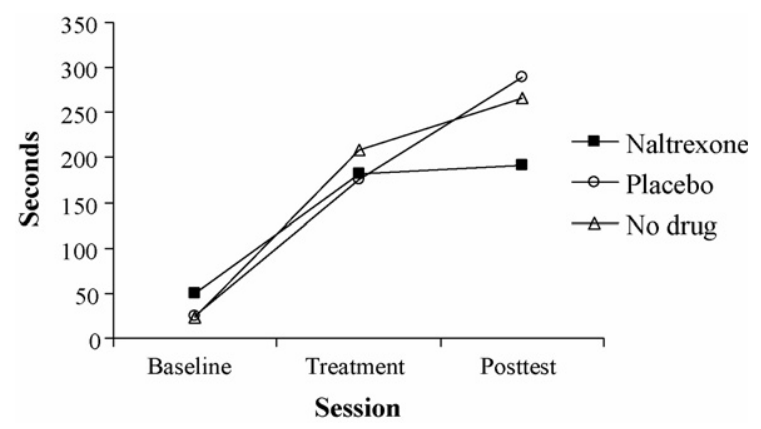

Fig. 1. Duration of time spent with feared animal during the BAT.

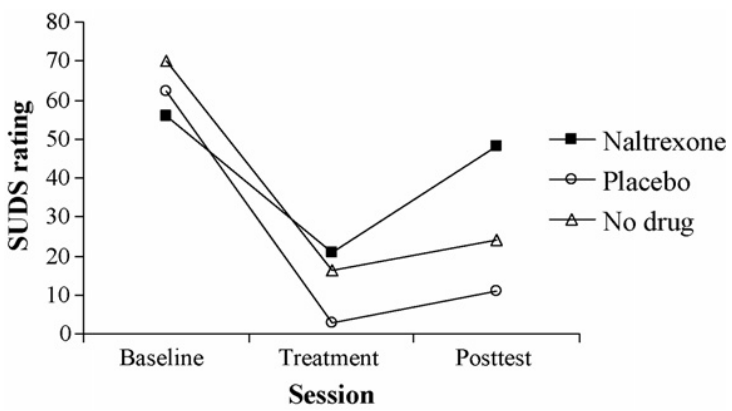

Fig. 2. SUDS ratings during the BAT. 
Table 3

Predictors of SUDS ratings during the BAT

\begin{tabular}{lcrr}
\hline Variable & Regression coefficient & S.E. & $t$ \\
\hline Covariates & & & 15.257 \\
$\quad$ Past treatment & 16.174 & 1.014 & 1.06 \\
$\quad$ Years of phobia & .564 & & .56 \\
Time effects & & 4.272 & 1.50 \\
$\quad$ Time & 6.396 & 2.016 & -.25 \\
$\quad$ Time & -.498 & & $-1.82^{*}$ \\
Group effects & & 15.054 & -.82 \\
$\quad$ Placebo & -27.442 & 14.257 & $2.59^{* *}$ \\
$\quad$ No drug & -11.629 & 2.586 & \\
$\quad$ Placebo $\times$ Time & 6.706 & & \\
\hline
\end{tabular}

Note. Predictors of SUDS ratings during the behavioral avoidance test (BAT) from baseline through posttest determined by mixed effects regression with available data.

* $P<.10$.

** $P<.05$.

\subsection{SUDS rating during BAT}

Longitudinal analysis of available SUDS data during the BAT showed a significant Group $\times$ Time interaction between the placebo contrast and the linear time trend and a nonsignificant interaction between the no drug contrast and the linear time trend (see Table 3). Fig. 2 displays mean SUDS ratings over time during the BAT for the three treatment groups with available data. Over time, the placebo group reported significantly lower SUDS ratings during the BAT compared to the naltrexone group. The no drug group was not significantly different from the naltrexone group over time.

\section{Discussion}

The purpose of this study was to investigate the effects of naltrexone on fear and avoidance behavior in a specific phobia sample that received one-session exposure treatment. As expected, after treatment, participants who were given placebo or no drug were able to stay in the room with a feared animal significantly longer during the BAT as compared to phobics who were given naltrexone. Across time, phobics given naltrexone had significantly higher levels of anxiety during the BAT as compared to the placebo group, but a statistically significant difference was lacking when the naltrexone group was compared to the no drug group. In general, the results suggest that treatment was less effective for the naltrexone group, which is consistent with the theory that endorphins and opioid receptors play an important role in in vivo exposure treatment.

To our knowledge, the present study is the first to demonstrate that naltrexone substantially reduces the duration of time participants can tolerate being near a feared animal during a behavioral assessment. The relative importance of this finding echoes the construct of avoidance as it pertains to adaptation via the endogenous opioid system. Although others have measured avoidance via distance to the phobic stimuli, steps in treatment, and drop out (Arntz et al., 1993; Merluzzi et al., 1991), such measures may not parallel the effects of the endogenous opioid system. Theoretically, the analgesic effects of the endogenous opioid system may not be as effective if the person leaves the exposure room quickly. Endogenous opioids may assist 
participants in staying in the room longer to allow the experience of anxiety reduction. This internal anxiety reduction is central to a positive treatment process. Within the present study, we provide some supportive empirical evidence for such assumptions.

Studies comparing antagonist versus placebo groups on self-report measures of anxiety have yielded inconsistent findings. Some studies have revealed that phobics given naltrexone have higher levels of anxiety after treatment as compared to those given placebo (Egan et al., 1988; Merluzzi et al., 1991), while others have detected a lack of significant group differences (Arntz et al., 1993). In the present study, self-reported post-treatment anxiety as measured by SUDS was substantially greater in the naltrexone group compared to placebo. However, this difference was not evidenced when comparing naltrexone with the no drug group.

The nonsignificant SUDS findings between the naltrexone and no drug groups may suggest that expectations about the drug could have bolstered the effect between the naltrexone and placebo condition. Although participants were not told whether the drugs would help or impede treatment, participants in the placebo group may have expected that the drug would help during treatment. Prior research supports the assumption that expectations can influence endogenous opioids (Haour, 2005). An alternative explanation is that low power from a small sample size and/ or specific thresholds for anxiety and duration during treatment may have influenced the results. Given that duration estimates did not appear amenable to expectation and that self-report data trended in the correct direction, it is plausible that a larger sample size would have afforded the expected results. Furthermore, participants were treated until both their anxiety level and duration of contact fell below a certain threshold, which possibly influenced the results. Plausibly, the naltrexone group rebound of SUDS ratings during the posttest may have been more dramatic if participants were not required to meet a particular anxiety and duration threshold during treatment.

Despite the encouraging findings, certain possible limitations should be mentioned. Bias may have been introduced by the lack of a blind in the no drug control group. Such concern is minimized, however, by similar response patterns between the placebo group and no drug group on the duration measure and the pattern of SUDS responses, with the placebo group having the greatest SUDS reduction at posttest. An additional concern relates to differential anxiety responses from drug side effects. Although plausible, side effect moderated responses were not probable because (a) the only participant to report side effects dropped out early, (b) there were no differential drop out rates among groups, and (c) the naltrexone group did not show selectively greater SUDS ratings compared with the no drug control when assessed immediately after treatment. Other factors such as lack of self-control influencing the results were also ruled out because there was no unilateral evidence of a selective bias across each phase of the study and other selective bias factors such as demographic differences were not evident.

In conclusion, the findings of this study support a link between the endogenous opioid system and avoidance behavior in specific phobics. These preliminary results need to be replicated with a larger sample size. Avoidance behavior seems to be an excellent first step in indirectly elucidating the effects of the endogenous opioid system. Although the present study does not report distance, future research should couple duration with a distance measure to fully understand opioid-mediated avoidance behavior. Utilizing other measures which more directly assess the effects of the endogenous opioid system could also be very informative. One potential avenue to pursue may be to study levels of $\beta$-endorphin, an opiate-active peptide, during onesession exposure treatment (Carr, 1996; Thyer \& Matthews, 1986). Lastly, investigating whether a non-addictive opiate agonist enhances treatment outcome could be useful. Opiate agonists bind to receptors, and then mimic the action of naturally occurring endogenous opioids (Venes et al., 
2001). It is suggested that a study is conducted comparing groups given an opiate agonist, placebo, or no drug with BAT duration, SUDS, and distance as outcomes. If the agonist group has the best outcomes, then the combination of one-session exposure treatment and an opiate agonist might be a viable treatment package for specific phobics.

\section{Acknowledgements}

We are grateful to Anna Magner for conducting sessions and assisting with coordinating responsibilities for this study. Many thanks to Emalee Fields, Kristin Grumbine, Erin Seligson, and Lynne Turner for conducting sessions. We would like to acknowledge Ellen Koch for providing manuals and treatment animals used in this study. Finally, thanks to Lynn Plew who provided outstanding care for the animals.

\section{References}

Amanzio, M., \& Benedetti, F. (1999). Neuropharmacological dissection of placebo analgesia: expectation-activated opioid systems versus conditioning-activated specific subsystems. The Journal of Neuroscience, 19(1), $484-494$.

American Psychiatric Association. (1994). Diagnostic and statistical manual of mental disorders (4th ed.). Washington DC: Author.

Arntz, A., Merckelbach, H., \& de Jong, P. (1993). Opioid antagonist affects behavioral effects of exposure in vivo. Journal of Consulting and Clinical Psychology, 61(5), 865-870.

Barlow, D. H. (1988). Anxiety and its disorders: the nature and treatment of anxiety and panic. New York: The Guilford Press.

Besson, A., Privat, A. M., Eschalier, A., \& Fialip, J. (1996). Effects of morphine, naloxone and their interaction in the learned-helplessness paradigm in rats. Psychopharmacology (Berl), 123, 71-78.

Booth, R., \& Rachman, S. (1992). The reduction of claustrophobia-I. Behaviour Research and Therapy, 30(3), $207-221$.

Carr, J. E. (1996). Neuroendocrine and behavioral interaction in exposure treatment of phobic avoidance. Clinical Psychology Review, 16(1), 1-15.

Diggle, P. J., Liang, K. Y., \& Zeger, S. L. (1994). Analysis of longitudinal data. Oxford, England: Clarendon Press.

Egan, K. J., Carr, J. E., Hunt, D. D., \& Adamson, R. (1988). Endogenous opiate system and systematic desensitization. Journal of Consulting and Clinical Psychology, 56(2), 287-291.

First, M. B., Spitzer, R. L., Gibbon, M., \& Williams, J. B. W. (1996). Structured clinical interview for DSM-IV Axis I Disorders-Non-Patient edition. New York: Biometrics Research Department.

Haour, F. (2005). Mechanisms of the placebo effect and conditioning. Neuroimmunomodulation, 12, 195-200.

Hunziker, M. H. L. (1992). Opioid nature of learned helplessness and stress-induced analgesia observed without reexposure. Behavioural Pharmacology, 3, 117-121.

Hyson, R. L., Ashcraft, L. J., Drugan, R. C., Grau, J. W., \& Maier, S. F. (1982). Extent and control of shock affects naltrexone sensitivity of stress-induced analgesia and reactivity to morphine. Pharmacology, Biochemistry and Behavior, 17, 1019-1025.

Koch, E. I., Spates, C. R., \& Himle, J. A. (2004). Comparison of behavioral and cognitive-behavioral one-session exposure treatments for small animal phobias. Behaviour Research and Therapy, 42, 1483-1504.

Kranzler, H. R., Kadden, R. M., Babor, T. F., Tennen, H., \& Rounsaville, B. J. (1996). Validity of the SCID in substance abuse patients. Addiction, 91(6), 859-868.

Maier, S. F., Sherman, J. E., Lewis, J. W., Terman, G. W., \& Liebeskind, J. C. (1983). The opioid/nonopioid nature of stress-induced analgesia and learned helplessness. Journal of Experimental Psychology: Animal Behavior Processes, 9(1), 80-90.

Marks, I. M. (1987). Fears, phobias, and rituals: panic, anxiety, and their disorders. New York: Oxford University Press.

Menzies, R. G., \& Clarke, J. C. (1993). A comparison of in vivo and vicarious exposure in the treatment of childhood water phobia. Behaviour Research and Therapy, 31(1), 9-15.

Merluzzi, T. V., Taylor, C. B., Boltwood, M., \& Gotestam, K. G. (1991). Opioid antagonist impedes exposure. Journal of Consulting and Clinical Psychology, 59(3), 425-430.

Ost, L.-G., Johansson, J., \& Jerremalm, A. (1982). Individual response patterns and the effects of different behavioral methods in the treatment of claustrophobia. Behaviour Research and Therapy, 20, 445-460. 
Rang, H. P., \& Dale, M. M. (1991). Pharmacology. New York: Churchill Livingstone Inc.

Riskind, J. H., Beck, A. T., Berchick, R. J., Brown, G., \& Steer, R. A. (1987). Reliability of DSM-III diagnoses for major depression and generalized anxiety disorder using the structured clinical interview for DSM-III. Archives of General Psychiatry, 44, 817-820.

Thyer, B. A., \& Matthews, J. (1986). The effect of phobic anxiety on plasma $\beta$-endorphin: a single-subject experiment. Behaviour Research and Therapy, 24(2), 237-241.

Venes, D., Thomas, C. L., Egan, E. J., Morelli, N. A., Nell, A. D., \& Houska, A. (Eds.). (2001). Taber's cyclopedic medical dictionary (19th ed.). Philadelphia, PA: F.A. Davis Company.

Verbeke, G., \& Molenberghs, G. (2000). Linear mixed models for longitudinal data. New York: Springer.

Wolpe, J. (1969). The practice of behavior therapy. New York: Pergamon Press. 